\title{
Continued Testing of the Cannon Caliber Electromagnetic Gun System (CCEMG)
}

\author{
By: \\ M.D. Werst \\ C.E. Penney \\ T.J. Hotz \\ J.R. Kitzmiller
}

9th EML Symposium, Edinburgh, Scotland, May 1998

PR -244

Center for Electromechanics

The University of Texas at Austin

PRC, Mail Code R7000

Austin, TX 78712

(512) 471-4496 


\title{
Continued Testing of the Cannon Caliber Electromagnetic Gun System (CCEMG)
}

\author{
M.D. Werst, C.E. Penney, T.J. Hotz, and J.R. Kitzmiller \\ Center for Electromechanics, The University of Texas at Austin
}

\begin{abstract}
The cannon caliber electromagnetic gun system is based upon a compulsator driven $30 \mathrm{~mm}$ rapid fire railgun system. The objective of the program was to develop a compact, lightweight test bed capable of launching three, five round salvos of $185 \mathrm{~g}$ integrated launch packages to $1.85 \mathrm{~km} / \mathrm{s}$ at a firing rate of $5 \mathrm{~Hz}$. Per contractual requirements, the pulse power system is also size compatible with the Amphibious Assault Vehicle. The pulse power system was developed around a fourth generation air-core, 4-pole rotating armature, self-excited, compulsator design. Although the contract for this effort has expired, the system continues to be used in part to demonstrate compulsator driven railgun technology. This system has performed seven single shots using identical control settings for each shot, which is the first such experience using a compulsator driven railgun system.
\end{abstract}

This paper describes the experimental set-up for the demonstrations and compares the generator, converter, gun switch, and launcher performances for each shot.

\section{INTRODUCTION}

The CCEMG (cannon caliber electromagnetic gun) system became operational for single shot testing in early 1996. Six single shot tests were performed to incrementally bring the pulse power system up to the maximum performance obtainable at $8,250 \mathrm{rpm}$ with a minimal number of tests [1]. The single shot tests were successful in commissioning the pulse power system and verifying simulation codes. The remaining contractual efforts focused on multishot capability [2]. Several previously published papers present optimization and design of the entire pulsed power system and railgun as well as test results for early system commissioning [3]-[5]. This paper presents test results for seven single shot tests performed with identical control settings. Although the energy levels are nowhere near the system's capability, the tests demonstrate performance repeatability in a pulse power system used infrequently and given little to no attention for months at a time.

CCEMG testing was discontinued in the fall 1996, however over the course of a year several demonstration tests were performed. Gun-shot level system parameters were chosen that allow the system to operate within a comfortable design

Manuscript received May 1, 1998

M.D. Werst may be contacted at 512-471-4496, fax 512-471-0781, m.werst@mail.utexas.edu.

This research was supported by U.S. Army ARDEC under contract no. DAAA21-92-C-0062. Funding was provided by the University of Texas. margin and minimum maintenance. As of January 1998, seven tests have been performed with identical shot parameters.

\section{SYSTEM DESCRIPTION}

\section{Pulsed Power System}

The pulse power system consists of the compulsator (CPA), field coil converter (FCC), gun switch module (GSM) and the railgun GMU (gun module unit) (Fig. 1). The compulsator is a four pole, rotating armature, self-excited air core configuration. The compulsator is capable of delivering 1.2 MJ to the railgun for three, five round salvos at a shot rep rate of $5 \mathrm{~Hz}$. The compulsator stores $40 \mathrm{MJ}$ at $12,000 \mathrm{rpm}$ and weighs $2,045 \mathrm{~kg}$. Rotor speeds have been limited to $8,500 \mathrm{rpm}$ due to assembly damage of an outer banding component. The compulsator and railgun performance levels and geometries were optimized to deliver ILPs (integrated launch packages) to a muzzle energy of $316 \mathrm{~kJ}$.

\section{System Layout}

The pulse power system, main controller, data acquisition and auxiliaries are all packaged in a $42 \mathrm{ft}$ long trailer. This trailer has electrical service provided by the CEM-UT facility to power on-board systems and the CPA drive motor (Figs. 2 and 3). The railgun is positioned on the south side of a large highbay door and is connected the GMU through a ground trench using six, $28 \mathrm{ft}$ long flexible hexapolar cables. The compulsator is protected by redundant auxiliaries powered from an externally located diesel generator set. The CPA is connected to a $400 \mathrm{hp}, 12,000 \mathrm{rpm}$ ac induction motor, which is in turn protected from rotor discharge decelerations via a high speed wet disk clutch. The motor also provides dynamic braking capability. A redundant wet disk brake located with the clutch brakes the CPA rotor in the event of a power failure.

\section{Power Electronics}

Solid state switches comprise the full wave rectifier/inverter bridge (RIB) for the field winding as well as the GSM. Rectification and inversion are achieved using a $95 \mathrm{MW}$ thyristor bridge. The RIB utilizes Powerex TD-20 (100 mm) devices in a two series, three parallel configuration per leg and includes a snubber circuit. The GSM utilizes 40 parallel Westcode N750Ch45 devices and is presently operating without a snubber.

A coaxial explosive opening switch (EOS) is used for overcurrent and thermal protection of the compulsator. The EOS 


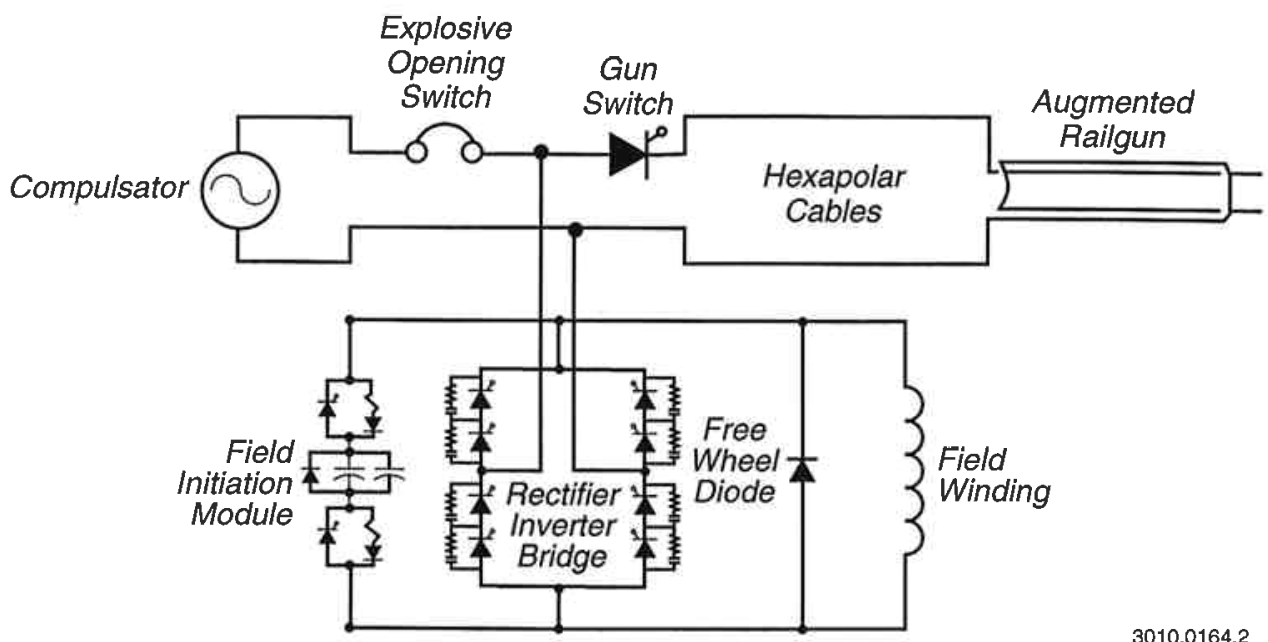

Fig. 1. CCEMG electrical schematic.

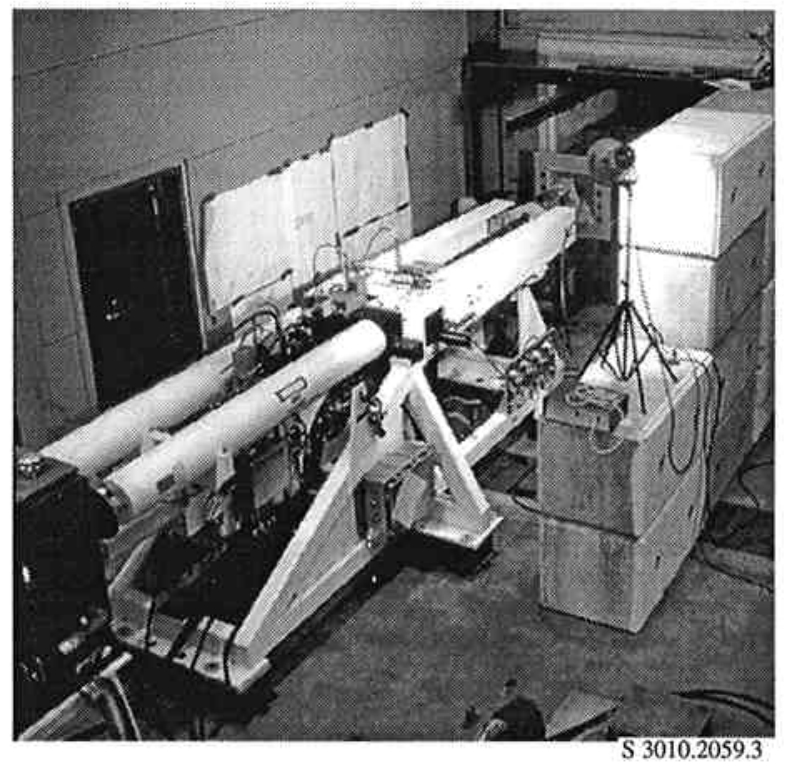

Fig. 2. CCEMG railgun and autoloader.

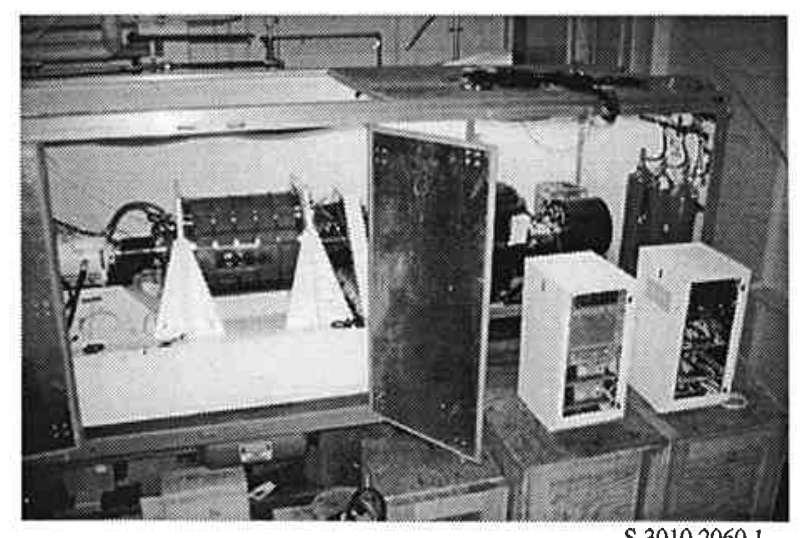

Fig. 3. CCEMG system. is designed to handle current and action of both the field coil and gun circuits. The switch consists of cylindrical aluminum elements with multiple stress risers gaps. Detonation of $\mathbf{1 5}$ grain Primacord ${ }^{\mathrm{TM}}$ creates the physical gap necessary to dissipate all of the inductive energy stored in the system.

\section{Railgun}

The CCEMG is a $2.25 \mathrm{~m}$ long series augmented configuration with a $1.75 \mathrm{~cm} \times 3.94 \mathrm{~cm}$ rectangular bore (Fig. 4). The railgun is water cooled for rapid fire operation and is mounted to a high performance autoloader that is capable of delivering up to $15,185 \mathrm{~g} \mathrm{ILP}$ at a rep rate of 300 rounds $/ \mathrm{min}$. The railgun is compliantly mounted to mitigate recoil loads and the autoloader has a maximum insertion force capability of 5 kips $(2,300 \mathrm{~kg})$. The gun is fired into an $8.0 \mathrm{~m}$ long steel flight tube located inside concrete bunkers. The flight tube holds the velocity make-screens and a target chamber where soft catches are attempted using rags and plywood.

\section{Armature}

Simple, duel contact solid armature projectiles were fired for the series of tests (Fig. 5). The armatures were machined from 7475-T654 aluminum plate and have identical rail interferences and sidewall clearances; the absolute dimensions did not change. The average projectile mass was $133.67 \mathrm{~g}$ and did not vary by more than $4 \mathrm{~g}$. The armatures were loaded using the autoloader in manual mode of operation. The armatures were simply loaded into the 15 round linear clip and indexed to the proper position. The hydraulically actuated rammer pawl extracts the armature from the clip and correctly positions it into the breech of the gun. Insertion forces are not determined precisely with the automatic loading system, however the armatures and loading mechanism were designed to insertions loads between 3 to 5 kips $(1,300-2,300 \mathrm{~kg})$. The recovered armature (run \#383) shown in Fig. 5 weighs $4.1 \mathrm{~g}$ less than its initial mass of $133.5 \mathrm{~g}$. 


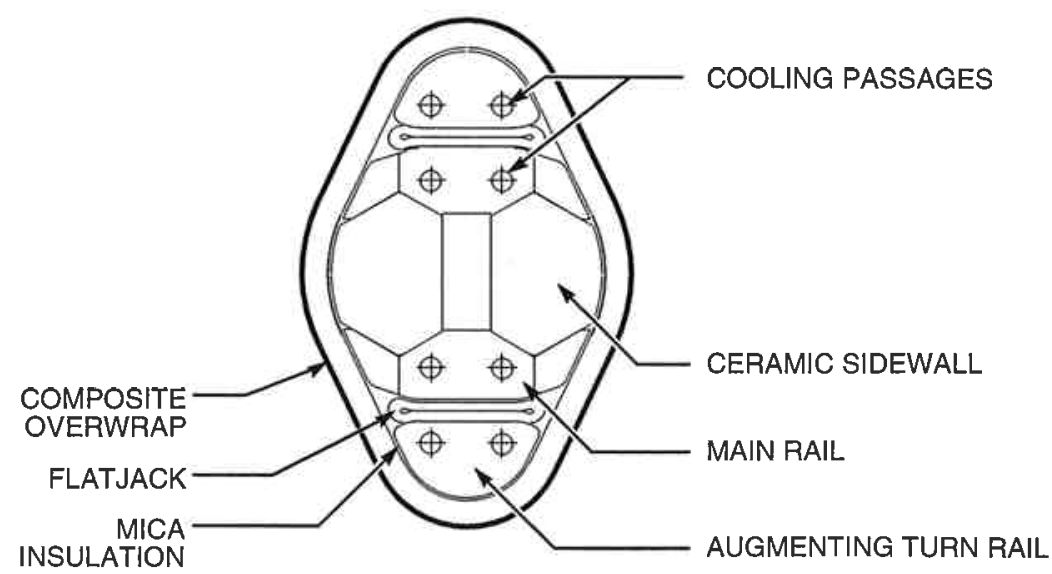

3010.0107

Fig. 4. Launcher cross section.

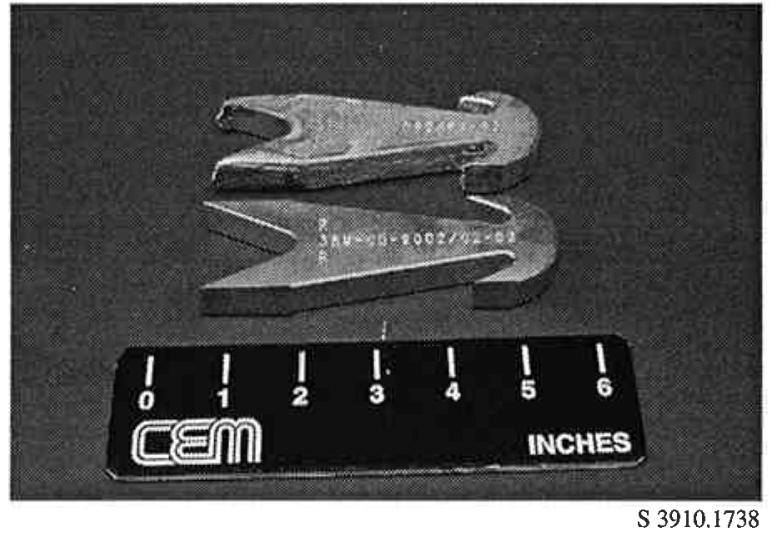

Fig. 5. Solid armature projectiles; before and after.

TEsTING

\section{System Operation}

For a typical test, a simulation is performed to predict performance and timing parameters. System operation is initiated by the operator "keying" in setup parameters and commands at the RCU (remote control unit) which is linked optically to the main system controller, known as the weapon controller, located in the trailer. Although a single operator controls the test, several people are involved for data acquisition, observation, and perimeter guards. The auxiliary system is powered up and a checklist completed to ensure all systems are functioning. A rotor speed is entered at the RCU and the field initiation module (FIM) begins charging to the desired voltage level. Motoring to 7,000 rpm requires only about $90 \mathrm{~s}$ at which time the operator initiates a "charge-arm drive" command which checks for speed matching and drops the brushes. At this time the weapon controller turns the control over to the FFCM (firing and fault control monitor). Assuming all of the input variables have been satisfied, the FFCM discharges the FIM into the field coil and begins gating the FCC (field coil converter) at gate angles determined by the cycle portion encoder and field current begins to increase. At a pre-determined field current, the FCC switches into freewheel mode (stops gating) and the FFCM waits for the next open circuit voltage cycle before triggering the gun switch module (GSM) at its predetermined firing angle. The closing of the GSM completes the gun circuit and the gun fires. The projectile exits at or near current zero and the GSM opens at that time. After a preset delay, the FCC begins gating at the proper inverter angles that, with the absence of the free wheel diode between the field coil terminals, would direct current back into the compulsator, thus reclaiming the field energy. Field energy reclamation mode of operation has not been demonstrated as of the writing of this paper.

\section{Pulsed Power System Performance}

Table 1 lists the performance parameters for the seven gun shots performed. Field charging is initiated by the discharge of the FIM into the field coil. The FIM charge rate is set with a trim pot and the charge amplitude set manually using an analog gage. The average field charging time for the seven tests is $227 \mathrm{~ms}$, which measured from the beginning of FIM discharge to the beginning of the gun pulse. The range of charging times did not vary by more than $8 \mathrm{~ms}$. An average of 52 electrical cycles were required to charge the field coil; one electrical period at 7,000 rpm is $4.3 \mathrm{~ms}$. The FFCM uses the open circuit voltage information to determine when the proper field coil excitation has been reached. 
Table 1. CCEMG demo shot data from December 1996 to August 1997.

\begin{tabular}{|c|c|c|c|c|c|c|c|c|c|}
\hline Parameter & Shot \#7 & Shot \#8 & Shot\#9 & Shot\#10 & Shot\#11 & Shot\#12 & Shot\#13 & Average & $\begin{array}{l}\text { Standard } \\
\text { Deviation }\end{array}$ \\
\hline$\overline{\text { Run \# }}$ & 379 & 382 & 383 & 395 & 396 & 401 & 402 & - & - \\
\hline Date of Test & $12 / 19 / 96$ & $2 / 25 / 97$ & $2 / 26 / 97$ & $6 / 23 / 97$ & $6 / 24 / 97$ & $8 / 12 / 97$ & $8 / 13 / 97$ & - & - \\
\hline Excitation Speed (rpm) ${ }^{*}$ & 7042 & 7081 & 7075 & 7109 & 7101 & 7042 & 7092 & 7077 & 27 \\
\hline Nominal FIM Charge (kV) & 2 & 2 & 2 & 2 & 2 & 2 & 2 & 2 & - \\
\hline Peak Field Current (kA) & 23.0 & - & 23.7 & 23.6 & 23.3 & 23.7 & 23.5 & 23.5 & 0.3 \\
\hline Field Rise Time (ms) & 231 & - & 223 & 226 & 226 & 230 & 226 & 227 & 3 \\
\hline Peak AC Voltage (V) & 1816 & 1818 & 1827 & 1825 & 1809 & 1836 & 1827 & 1823 & 9 \\
\hline Discharge Speed (rpm)* & 6579 & 6564 & 6579 & 6579 & 6593 & 6550 & 6579 & 6575 & 14 \\
\hline GSM Firing Angle (deg) & 8.7 & 7.9 & 8.7 & 8.3 & 0.0 & 0.0 & 0.0 & - & - \\
\hline Voltage@ GSM Trigger(V) & 280 & 154 & 150 & 139 & 0 & 0 & 0 & - & - \\
\hline Peak Gun Current (kA) & 486 & 493 & 499 & 490 & 483 & 491 & 483 & 489 & 6 \\
\hline Muzzle Current (kA) & 74 & 120 & 110 & 98 & 80 & 104 & 90 & 97 & 16 \\
\hline Armature Mass (g) & 133.8 & 133.4 & 133.5 & 133.7 & 133.6 & 133.9 & 133.8 & 133.7 & 0.2 \\
\hline Prọjo Velocity $(\mathrm{m} / \mathrm{s})$ & 1327 & 1368 & 1344 & 1344 & 1287 & 1353 & 1332 & 1336 & 26 \\
\hline
\end{tabular}

*Calculated from OC voltage data

Fig. 6 shows the current measured at the ac side of the FCC bridge module for shot \#9. Field current is measured using a Pearson current transformer. Current measurements on the $\mathrm{dc}$ side require a calibrated shunt resistor which was not available for these tests. Fig. 7 shows the resulting CPA open circuit voltage for shot $\# 9$.

Gun current is measured using a Rogowski coil imbedded in the breech of the gun. Raw Rogowski signals are recorded using a Nicolet Pro 92 digital oscilloscope at $2 \mathrm{MHz}$ and integrated numerically. A scale factor was derived by attaching a calibrated current viewing resistor to the muzzle of the gun and performing numerous short circuit tests up to $200 \mathrm{kA}$ current levels.

Current plots from each of the tests show current rise times that collaborate well with the GSM firing angle. As can be seen from Fig. 8, the current rise times for shots \#7-10 are slightly faster than for shots 11,12 and 13 in which the GSM was triggered close to $0^{\circ}$. Triggering the GSM at $0^{\circ}$ was not done intentionally. Apparently, the GSM firing angle was either incorrectly entered into the input files, or the data was incorrectly communicated to the FFCM, or the FFCM malfunctioned. The FFCM shares a single cycle portion encoder for both the GSM and the FCC and the FCC gating feature functioned properly. Additionally, since this occurred on three successive shots, it is more likely that there is a problem with the data communication between the weapon controller and the FFCM.

Gun currents superimposed on a single plot show consistent current amplitudes. The average current from the seven shots (7 through 13) is $489 \mathrm{kA}$ with a standard deviation of $6 \mathrm{kA}$. Exit currents were measured at the point in time that the muzzle voltage just begins to rise (Fig. 9). This is obviously not a well defined point and therefore muzzle currents listed in table 1 show some variability; an average of $97 \mathrm{kA}$ and a standard deviation of $16 \mathrm{kA}$.

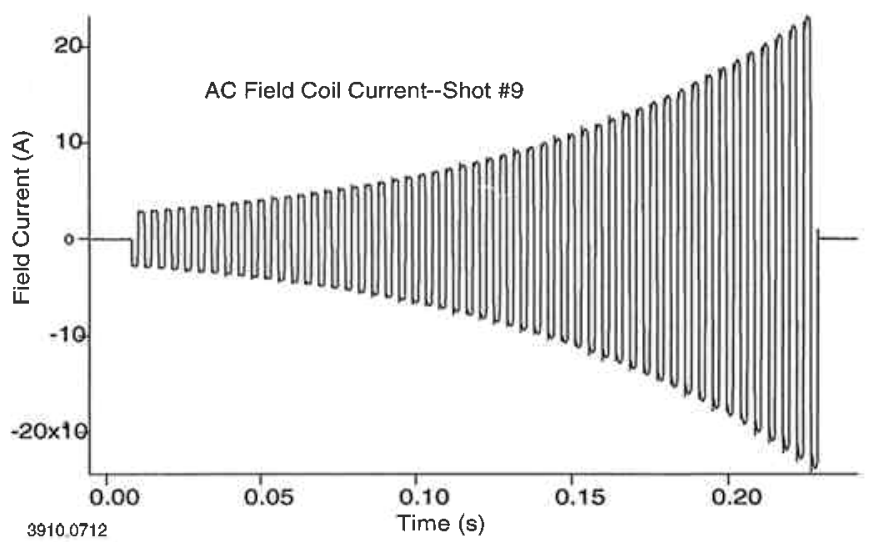

Fig. 6. Field coil current for shot \#9. (Note: field current measured on side of rectifier/inverter bridge module.)

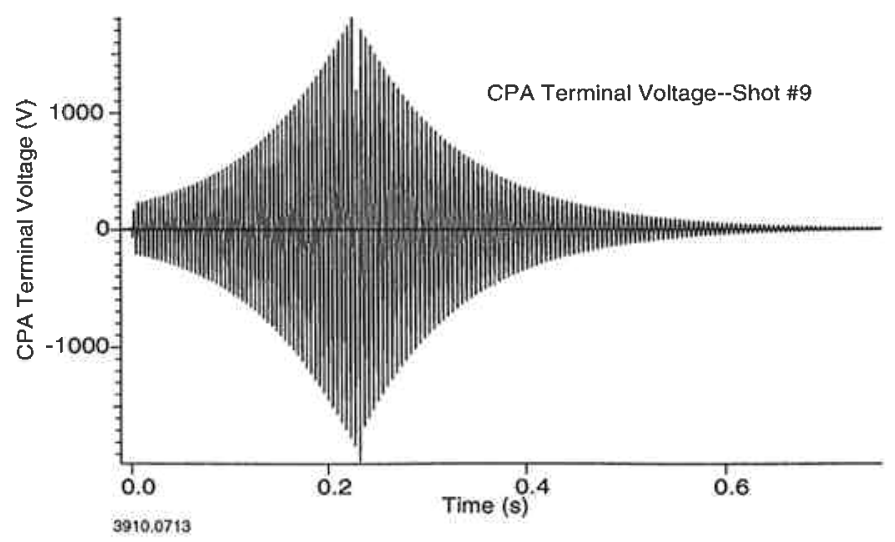

Fig. 7. CPA open circuit voltage for shot \#9. 


\section{Gun Performance}

Projectile velocities are measured using aluminum foil make-screens with $1 \mathrm{kV}$ excitation. Fixtures within the flight tube maintain a consistent relative distance of $393.9 \mathrm{~mm}$ between make-screens. In an attempt to prevent premature triggering of the make screens by pressure waves or particles launched ahead of the armature, a sheet of mylar is taped to the front of the flight tube. The average velocity for the seven tests is $1,336 \mathrm{~m} / \mathrm{s}$ with a standard deviation of $26 \mathrm{~m} / \mathrm{s}$.

An attractive feature of single phase compulsator gun systems is that inductive gun energy is reclaimed by the compulsator passively. This can be seen in a plot of gun power and breech energy for shot \#7 (Fig. 10). The compulsator reclaims the gun power in the form of stored energy in the rotor. The breech energy is determined by integrating the product of the breech voltage and gun current. Dividing the kinetic energy of the projectile by the breech energy at armature exit, the breech efficiency of the gun is calculated to be $50 \%$. The kinetic energy of the projectile calculation uses the recovered projectile mass. The effective launcher inductance gradient is calculated using the integral of the current squared, velocity and armature mass data. An average value of $1 \mu \mathrm{H} / \mathrm{m}$ was obtained for all tests and is consistent with tests performed at ARL on launchers IIA and IIB [6].

\section{System Maintenance}

To date, the CCEMG system has performed 402 motoring runs and 13 gun shots. The compulsator has yet to be disassembled for inspection. Each gun shot requires the loading and subsequent unloading of the explosive opening switch. The EOS is triggered off of a delay timer after the gun pulse as precautionary measure. EOS elements used by the CCEMG system are identical to those used by other CEM-UT compulsator programs and the components are fully interchangeable. This makes personnel training and servicing simpler and less time consuming. Generally, it takes about one hour to unload and reload the EOS.

After each shot, visual bushar inspections are performed in addition to spot checks with a multimeter. Break-away torque of the compulsator is measured prior to each motoring run. Visual inspection of the auxiliary generator fuel and oil level is also checked before each run. Bearing/damper oil and coolant levels and pressures are checked by the control system prior to every motoring run. Nitrogen and vacuum circuits are also checked by the control system at this time.

The directional preloading mechanisms called "flatjacks" did not require maintenance [3]. The primary flatjacks were pressurized to $13 \mathrm{ksi}(89.6 \mathrm{MPa})$ during the initial gun installation and have not required adjustments. The secondary flatjacks which preload the main rails between the augmenting turn cross-over and the muzzle of the gun have remained at 5 $\mathrm{ksi}(34.5 \mathrm{MPa})$ since the gun was installed.

Gun maintenance for the seven gun shots consisted of flushing the bore with compressed air and pushing an alcohol soaked scotch-brite pad through the bore multiple times. The

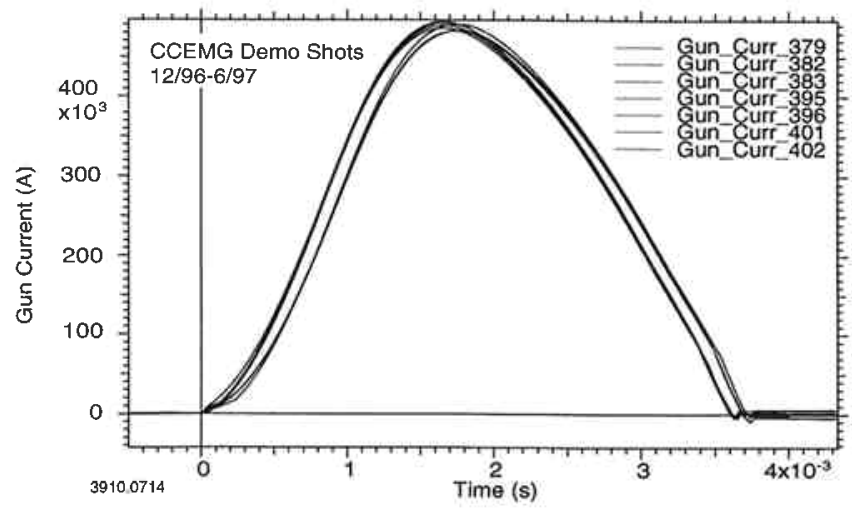

Fig. 8. Gun current plots for the seven gun shots 7 through 13.

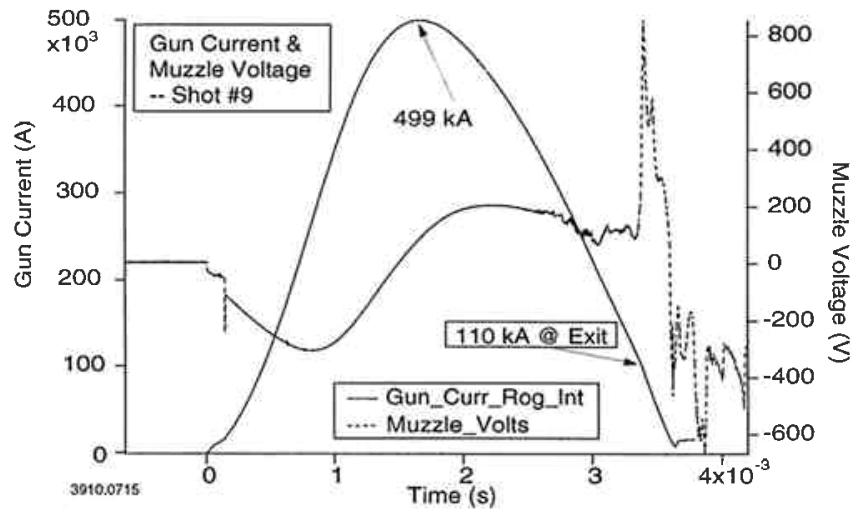

Fig. 9. Gun current and muzzle voltage for shot \#9.

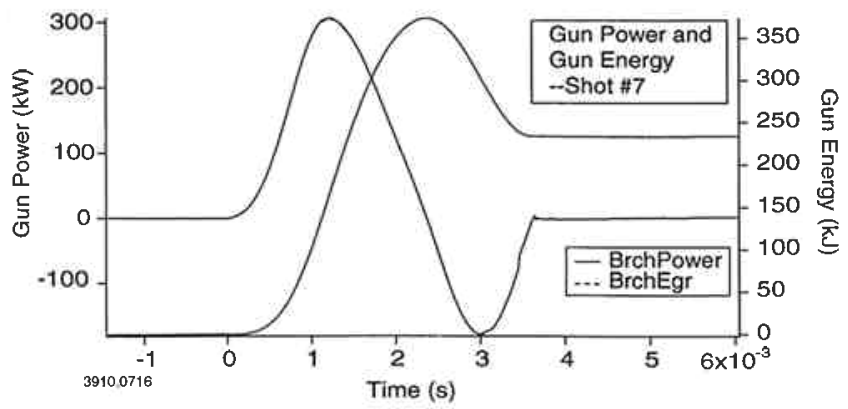

Fig. 10. Gun power and breech energy for shot \#7. 
gun shots produced an average muzzle current of $97 \mathrm{kA}$ which resulted in localized rail ablation at the muzzle. Rail surface roughness at the muzzle was dressed with a small flat file and cleaned with alcohol. Range preparation includes preparation of the velocity screens and repacking the rags and plywood in the range.

\section{CONCLUSIONS}

Seven railgun shots were performed with Cannon Caliber EM gun system over an eight month period. With the exception of the gun switch firing angle, all control settings were identical. System repeatability based on gun performance is very good; peak currents and projectile velocity measurements varied by only $2 \%$ and $3 \%$, respectively.

\section{ACKNOWLEDGMENTS}

The authors would like to acknowledge the numerous people from ARDEC, UDLP and CEM-UT that contributed to making the CCEMG system a reality. Funding for this effort has been provided by The University of Texas at Austin.

\section{REFERENCES}

[1] J.R. Kitzmiller, et al, "Laboratory testing of the pulse power system for the cannon caliber EM gun system (CCEMG)," IEEE Transactions on Magnetics, vol 33, no 1, January 1997.

[2] T.J. Hotz, C.E.. Penney, J.R. Kitzmiller, and M.D. Werst, "Single shot switch performance on the cannon caliber electromagnetic gun program," submitted to the 9th EML Symposium, Edinburgh, Scotland, April, 1998.

[3] M.D. Werst, T.J. Hotz, J.R. Kitzmiller, C.E. Penney, and R.M. Tellander, "Testing of the cannon caliber rapid fire railgun," IEEE Transactions on Magnetics, vol 33, no 1, January 1997.

[4] C.E. Penney and T.J. Hotz, "CCEMG switch testing," IEEE Transactions on Magnetics, vol 33, no 1, January 1997.

[5] B.T. Murphy, S.M. Manifold, and J.R. Kitzmiller, "Compulsator rotor-dynamics and suspension design," IEEE Transactions on Magnetics, vol 33, no 1, January 1997.

[6] A.E. Zielinski, M.D. Werst, and J.R. Kitzmiller, "Cannoncaliber electromagnetic launcher," IEEE Transactions on Magnetics, vol 33, no 1, January 1997. 